\title{
BIIBHECa
}

Biblioteca Universitaria

ISSN: 0187-750X

public@dgb.unam.mx

Universidad Nacional Autónoma de México

México

Araiza Díaz, Verónica

Pensar la sociedad de la información/conocimiento

Biblioteca Universitaria, vol. 15, núm. 1, enero-junio, 2012, pp. 35-47

Universidad Nacional Autónoma de México

Distrito Federal, México

Disponible en: http://www.redalyc.org/articulo.oa?id=28528264004

- Cómo citar el artículo

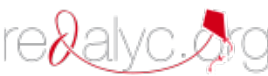

- Número completo

- Más información del artículo

- Página de la revista en redalyc.org

Sistema de Información Científica

Red de Revistas Científicas de América Latina, el Caribe, España y Portugal

Proyecto académico sin fines de lucro, desarrollado bajo la iniciativa de acceso abierto 


\section{Pensar la sociedad de la}

\section{información/conocimiento}

\section{Thinking about the information/knowledge society}

\section{Verónica Araiza Díaz*}

\section{Resumen}

En el presente trabajo se esbozan algunas líneas de reflexión fundamentales para la discusión en torno a la conceptualización de la sociedad de la información/conocimiento, desde una perspectiva teórico-social. Se plantean algunos elementos constitutivos de la llamada sociedad de la información, tales como: tecnología, economía, trabajo, redes, etcétera. Se discute sobre el tema -muchas veces formulado- de que los recientes cambios tecnológicos han dado origen a un tipo diferente de sociedad. Nos preguntamos si efectivamente estamos ante un nuevo modelo de sociedad o si nos encontramos ante una nueva función de la información en un mismo sistema, pero en un escenario distinto. Se destaca el hecho de que un nuevo tipo de sociedad implicaría que el conocimiento (teórico) impulsara la toma de decisiones en todos los ámbitos de la vida. Por otro lado, se hace referencia tanto al aspecto ético como ideológico de la información, para mostrar que no se trata de un fenómeno aislado sino que responde a diferentes contextos e intereses. De igual manera, se refieren las perspectivas o enfoques desde los que se puede abordar esta cuestión, ya que se trata de un tópico multifacético. Finalmente, se habla del rol del bibliotecario ante este panorama.

Palabras Clave: Información, sociedad de la información, sociedad del conocimiento, bibliotecología, conceptualización.

\section{Abstract}

This paper outlines some key lines of inquiry for the discussion of the conceptualization of the information/ knowledge society, from a social/theoretical perspective. Some elements of the so-called information society are discussed, such as: technology, economics, work, networks, etc... It is argued on the subject -often made- that recent technological changes have given rise to a different type of society, and if -indeed- this is a new model of society or if we have a new role of information in the same system, but in a different scenario. It highlights the fact that a new kind of society would mean that the (theoretical) knowledge will drive decision making in all areas of life.

On the other hand, reference is made to both the ethical and ideological aspects of information to show that it is not an isolated phenomenon but responds to different contexts and interests. Also, it refers to the perspectives and approaches from which one can address this issue, since this is a multifaceted topic. Finally, it discusses the role of the librarian in this scenario.

KeYwORDS: Information, information society, knowledge society, librarianship, conceptualization.

Maestría en Bibliotecología y Estudios de la Información, Facultad de Filosofía y Letras de la UNAM. Circuito interior, UNAM-CU, C.P. 04510, México D.F., México. Correo electrónico: veraiza@yahoo.com. 


\section{Introducción}

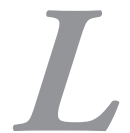

os conceptos de sociedad de la información y sociedad del conocimiento han tenido un desarrollo a lo largo de prácticamente cinco décadas: por lo tanto, existe una gran producción intelectual sobre esta temática. Por otro lado, no se trata de conceptos univocos pues han sido tratados -desde distintas áreas del conocimiento- por diversos autores, quienes les han otorgado determinados significados. De acuerdo con Becerra:

distintos objetos de análisis, focos de atención divergentes, metodologías opuestas, intenciones diferentes, conclusiones desparejas y prospectivas por momentos irreconciliables se conjugan en el elevado número de producciones que la sociedad informacional viene suscitando. ${ }^{1}$

Es decir, las concepciones sobre estos términos son bastante variadas toda vez que ellos mismos implican distintos aspectos de la sociedad a la que hacen referencia e incluso pueden involucrar concepciones distintas de la misma. Entonces, nos encontramos ante un par de conceptos ampliamente desarrollados y discutidos, pero que no significan lo mismo para todos los autores. Como sugiere de nuevo Becerra:

La complejidad del objeto de estudio (la sociedad informacional) impide que exista una metodología de abordaje consagrada como válida universalmente para proceder a un examen riguroso que se pretenda incuestionable. Por ello, además, a la hora de plantear temas vinculados a la "sociedad de la información" se dan cita actores tan heterogéneos como gobiernos de países centrales, gobiernos de países periféricos, empresas multinacionales de las industrias culturales, empresas multinacionales fabricantes de hardware y software, instituciones educativas, organismos técnicos de sectores económicos como el agro y la industria, centros de salud, organismos reguladores de transporte, investigadores, academias, organizaciones no gubernamentales, sociedades filantrópicas y clubes sociales, entre otros. ${ }^{2}$

1 Becerra, Martín. "La sociedad de la información" [en línea]. Lecciones del Portal. PortalComunicación.Com, p. 2.

2 Ibid., p. 3.
Por ello es necesario construir un panorama conceptual del tema general para poder entender la discusión de que es objeto, el contexto histórico y epistemológico en el que se da, para finalmente comprender el impacto que dichos conceptos tienen o pueden tener en el campo bibliotecológico.

Ahora bien, en lo que hace a la relación que tienen entre sí los conceptos sociedad de la información y sociedad del conocimiento es necesario hacer algunos comentarios. Primero, a veces son utilizados como sinónimos pero no lo son aunque están íntimamente ligados y por ello son tratados conjuntamente. Segundo, existe una convención que señala que la sociedad de la información es condición de la sociedad del conocimiento, que la primera tiene más que ver con la innovación tecnológica y la segunda con una dimensión más amplia de transformación social, cultural, económica y política; o dicho de otra manera, que la sociedad de la información es una etapa previa de este nuevo tipo de sociedad que nos llevará finalmente a la etapa del conocimiento.

No obstante esta interpretación común, considero que la distinción debe hacerse -antes que entre tipos de sociedad- entre los conceptos de información y conocimiento ${ }^{3}$, pues el debate sobre un nuevo tipo de sociedad (basada en ambos) está abierto y continúa, hay quien habla de uno u otro, o en singular o plural. Por lo tanto, en adelante hablaré de sociedad de la información/conocimiento en tanto elementos del mismo debate, pero no quiere decir que sean lo mismo.

Primero, me referiré un poco a los orígenes del concepto y del contexto histórico en el que surge. Más adelante, plantearé un panorama conceptual basado en los elementos de análisis que debe incluir el estudio de la sociedad de la información/conocimiento. Posteriormente, discutiré brevemente dichos elementos con la intención de mostrar los problemas que acarrea el tema. Finalmente, mostraré mis conclusiones que apuntan a la diversificación de enfoques de la materia.

3 De manera muy sencilla, se puede decir que la información es un conjunto de datos sobre algo, mientras que el conocimiento es el análisis o interpretación de dicha información, hecho por una persona que posee los elementos intelectuales para hacerlo. 


\section{Los orígenes y el contexto histórico}

Aunque el tema de la relación entre el conocimiento y la economía fue tratado por autores clásicos como Marx y Adam Smith, suele atribuirse el origen del concepto de sociedad de información/conocimiento a Daniel Bell ${ }^{4}$ quien al hablar de una sociedad postindustrial sugirió una transformación de la economía y de la sociedad, las cuales estarían ahora basadas en la información y el conocimiento. Pero poco antes otros autores se ocuparon del tema: Fritz Machlup ${ }^{5}$ desde la economía y Peter Drucker $^{6}$ desde el área de gestión; posterior a Bell, Yoneji Masuda ${ }^{7}$ abordó el tema desde la sociología.

Como vemos, los conceptos de sociedad de la información/conocimiento surgieron a partir de la década de los sesenta y han tenido una construcción teórica que se ha desarrollado desde entonces y hasta el día de hoy. Pero si hablamos del contexto histórico debemos ubicarnos en la llamada posmodernidad, más concretamente con el denominado capitalismo tardío, etapa caracterizada por la globalización y el neoliberalismo. De acuerdo con Castells ${ }^{8}$, esta fase consiste en una reconfiguración del sistema capitalista; en sus palabras es:

Un proceso de reestructuración profunda, caracterizado por una mayor flexibilidad en la gestión; la descentralización e interconexión de las empresas, tanto interna como en su relación con otras: un aumento de poder considerable del capital frente al trabajo, con el declive concomitante del movimiento sindical; una individualización y diversificación crecientes en las relaciones de trabajo; la incorporación masiva de la mujer al trabajo retribuido, por lo general en condiciones discriminatorias; la intervención del estado para desre-

4 BeLL, Daniel. The Coming of Post-Industrial Society.

5 Manchlup, Fritz. The Production and Distribution of Knowledge in the United States.

6 DruCKER, Peter F. The Age of Discontinuity: guidelines to our changing society.

7 Masuda, Yoneji. The Information Society as Post-Industrial Society.

8 Quien desarrolló de manera por demás amplia, en una obra de tres volúmenes, el concepto era de la información desde la perspectiva sociológica. gular los mercados de forma selectiva y desmantelar el estado de bienestar, con intensidad y orientaciones diferentes según la naturaleza de las fuerzas políticas y las instituciones de cada sociedad; la intensificación de la competencia económica global en un contexto de creciente diferenciación geográfica y cultural de los escenarios para la acumulación y gestión del capital. ${ }^{9}$

Podemos suponer, entonces, que este reacomodo del sistema pudo impulsar la construcción de la supuesta nueva sociedad fincada en la producción y manejo de información.

\section{Panorama conceptual}

En el gran tema de la sociedad de la información/conocimiento existen una serie de líneas de estudio que se desprenden del mismo y que han sido tratadas o desarrolladas por diversos autores de muy distinta procedencia a lo largo de varias décadas. Ellas resumen las principales ramas del argumento de la sociedad de la información/ conocimiento, las cuales son establecidas en función de los fenómenos en torno a los cuales cada una de ellas reflexiona. No se trata de que estas líneas se excluyan mutuamente o de que una no tenga que ver con otra. Yo diría que todo el fenómeno es fractal, es decir que las caras son las partes que explican el todo del fenómeno pero en modo alguno son el todo. Por ello es necesario ver las líneas por separado para luego poderlas integrar y así tener una mejor comprensión del problema.

Así pues, para Webster ${ }^{10}$ existen cinco formas básicas de distinguir una sociedad de la información y una sexta más compleja que es la que suscribe el propio autor. Nos encontramos entonces ante una serie de fenómenos que suponen un nuevo tipo de sociedad:

9 CAStells, Manuel. Prólogo: la red y el yo. En: La era de la información: economía, sociedad y cultura, p. 28.

10 Webster, Frank. The information society revisited. En: Handbook of new media: social shaping and consequences of ICTS. 
1. Innovación tecnológica. La propuesta es que el "volumen de las innovaciones tecnológicas debe conducir a una reconstitución del mundo social ya que su impacto es profundo". ${ }^{11}$ Esta línea refiere las llamadas "autopistas" de la información, trazadas justamente por las tecnologías de información y comunicación (TIC) y supone que la población debe ser experta para poder transitar por dichas vías.

2. Cambio ocupacional. En este punto presume que la mayoría de los empleos están vinculados a la creación y utilización de información, por lo tanto, al sector terciario o de servicios. Esto implicaría el poder transformador de la información, ya que indica que "la riqueza de la producción no proviene del esfuerzo físico, sino de las ideas, el conocimiento, las habilidades, el talento y la creatividad". ${ }^{2}$

3. Valor económico. Aquí nos encontramos ante las industrias de la información, tales como: educación, leyes, publicidad, medios, manufactura de computadoras, etcétera. Se trata entonces de una sociedad cuyas principales áreas de actividad económica se relacionan con la producción de bienes y servicios de información.

4. Flujos de información (espacio). Este aspecto se centra en las redes que acompañan a los flujos de información, las cuales impactan en la organización del tiempo y espacio. Por ello utiliza el término "sociedad red", desarrollado por autores como Castells. ${ }^{13}$

5. Expansión de símbolos y señales (cultura). Esta línea es la que se ocupa del aumento de la circulación de información en la vida cotidiana, lo que significa que nuestra cultura actual está mucho más cargada de información que las sociedades anteriores.

\footnotetext{
1 Ibid., p. 25.

2 Ibid., p. 29.

13 Castells, Manuel. Prólogo: la red y el yo, op. cit.
}

Pero el punto central es que el bombardeo de información provoca que la vida esté llena de simbolismos, con lo cual mucho de lo que vemos y hacemos es simulado.

6. Conocimiento teórico. Aquí, la sociedad de la información o-mejor dicho- sociedad del conocimiento sería aquella en la que el conocimiento teórico determina todas las decisiones de múltiples y variados aspectos de nuestra vida, desde las más simples a las más complejas. Este tipo de sociedad dependería entonces "de la generación y uso de la información/conocimiento". ${ }^{4}$

Por su parte, Becerra ${ }^{15}$ divide las líneas de reflexión en función de quienes abordan el fenómeno:

- Postindustrialistas. Esta línea propone que el capitalismo ha sufrido una transformación, que pasó del modo industrial (industria como motor del desarrollo económico) al informacional, "el conocimiento y la información se transformaron en insumos y productos estructurantes".

- El Estado. En este caso, los estados de los países centrales promueven estudios prospectivos sobre el cambio en sus estructuras de desarrollo, así surgen gran cantidad de documentos basados en tres aspectos fundamentales: liberalización, desregulación y competencia global.

- Los "gurús"; los tecnófilos. Esta vertiente refiere los grandes cambios tecnológicos y supone su efecto sobre "una masa presuntamente neutra e indiferenciada".

- Política y comunicación. Esta corriente se ocupa del análisis de las políticas de comunicación y de los actores que las formulan y ponen en práctica. Se trata de ver lo político de la comunicación y viceversa. Se enfoca mucho en las políticas públicas.

14 Webster, Frank, op. cit., p. 38.

15 Becerra, Martín, op. cit., p. 7-11. 
información, a través de ciertas competencias cognitivas, en instrumentos que nos permiten resolver problemas teóricos o prácticos. Es así como lo ve la UNESCO:

La información es lo que se transforma con un tratamiento adecuado, mientras que el conocimiento es lo que se produce. La producción del conocimiento se basa siempre en un nivel de conocimiento y en la transformación de la información. Lo que conduce a la producción de conocimiento es una forma de transmutación de la información, pero el conocimiento mismo se transforma en información para poder ser tratado y producir un nuevo conocimiento. En este "círculo virtuoso" estriba precisamente la innovación que permite nuevos aumentos de productividad en la producción de conocimiento. ${ }^{17}$

Desde esta perspectiva, información y conocimiento son parte del proceso de producción en términos de ciencia. Así que se trata de información científica y conocimiento teórico. Esta aclaración es importante en función de que los términos información y conocimiento pueden ser entendidos de múltiples maneras. Sin embargo, el concepto de sociedad de la información/conocimiento hace hincapié en la información y conocimiento científicos encaminados a la tecnología. De esta manera, autores como Drucker ${ }^{18}$ hacen referencia "al tecnoconocimiento; es decir, aquella modalidad de producción de conocimiento que acaba generando desarrollos tecnológicos e innovaciones, sean bienes, servicios, productos o procesos"19; por ello se habla de sistemas de I+D+i (investigación, desarrollo tecnológico e innovación).

Otro aspecto que debe ser afrontado es la cuestión de la información y el conocimiento entendidos como bienes, pues ¿se trata de bienes públicos o privados? La respuesta sería que ambos; es decir, hay dos perspectivas muy distintas de sociedad de la información/ conocimiento: una de ellas piensa en bienes privados y otra en bienes públicos. La primera promueve la mer-

17 UNESCO. "Sociedades en redes, conocimientos y nuevas tecnologías" [en línea]. En: Hacia las sociedades del conocimiento, p. 51.

18 Drucker, Peter F., op. cit.

19 Echeverría, Javier. Las repúblicas del conocimiento. En: Sociedad del conocimiento: propuestas para una agenda conceptual, p. 43. cantilización de la información y el conocimiento, como bienes que producen riqueza; se trata de la apropiación del conocimiento para fines comerciales. La segunda, en cambio, claramente piensa en el bien público, en aquello que construimos todos y al cual debemos acceder todos; se vincula entonces al tema de los derechos sociales y culturales, y concibe a la información/conocimiento como fuentes del desarrollo no sólo económico, sino social y cultural de la humanidad entera.

Por último, se debe mencionar el matiz ideológico de la información y el conocimiento, en virtud de que en los estudios sobre la sociedad de la información/conocimiento de pronto se habla de ellos como si fueran elementos neutrales, que no tienen implicaciones políticas. Evidentemente no es así, la información y el conocimiento forzosamente se relacionan con el poder ${ }^{20}$, quien los posee se coloca en una mejor posición frente a aquéllos que no lo hacen. En el contexto en que nos encontramos, justamente la información y el conocimiento adquieren un papel central que en otras épocas no tenían, al menos en términos comerciales, con lo cual se vuelven parte de intereses económicos y políticos aún más complejos. Pues, como lo expresa Morales"1: "la existencia de la información no es un hecho aislado, es un producto social; y dentro de esta sociedad existen jerarquías, principios de orden, grupos de poder".

Es por lo anterior que Mattelart sostiene que:

la noción de Sociedad de la Información no adquiere su
sentido sino en una configuración geopolítica. Proyec-
tos de sociedad contrastados se enfrentan y subentien-
den arquitecturas y usos muy diferentes de las redes
de información y de comunicación a escala planetaria. ${ }^{22}$

II.- Ahora bien, respecto al nuevo tipo de sociedad debemos recapitular para extraer los aspectos medulares que la identifican y así poder tematizarlos. A continuación presento -entonces- dichos aspectos:

\footnotetext{
20 Autores como Foucault han analizado la relación saber-poder.

21 Morales Campos, Estela. Sociedad e información. Omnia, p. 2.

22 MatTelaRt, Armand. La Sociedad de la información [en línea]: el enfrentamiento entre proyectos de sociedad, p. 5.
} 
Uso de tecnologías. Como sabemos, una de las características fundamentales de esta era es el gran uso de las TIC en la vida cotidiana, no sólo para fines instrumentales (laborales o comerciales), sino de ocio o recreación. Esto obviamente ha transformado la vida cotidiana; es decir, no sólo tiene que ver con la cantidad de dispositivos tecnológicos que usamos día con día y que nos ayudan a acortar distancias y tiempos, sino también con cómo eso ha impactado en la manera de relacionarnos y de entender el mundo de hoy.

Un punto nodal en este sentido es la relación entre tecnología y sociedad. De acuerdo con Castells ${ }^{23}$, la tecnología no determina la sociedad y ésta tampoco dicta el curso del cambio tecnológico, en sus palabras:

La capacidad o falta de capacidad de las sociedades para dominar la tecnología, y en particular las que son estratégicamente decisivas en cada periodo histórico, define en buena medida su destino, hasta el punto de que podemos decir que aunque por sí misma no determina la evolución histórica y el cambio social, la tecnología (o su carencia) plasma la capacidad de las sociedades para transformarse, así como los usos a los que esas sociedades, siempre en un proceso conflictivo, deciden dedicar su potencial tecnológico. ${ }^{24}$

Y más aún, el desarrollo o rumbo tecnológico de cada país dependerá del modelo de relación entre Estado y sociedad. ${ }^{25} \mathrm{O}$ sea que si se trata de un modelo estatista será el Estado quien impulse el desarrollo tecnológico de acuerdo a determinados intereses (nacionales), mientras que si hablamos de un modelo liberal, será el sector privado quien promueva el desarrollo tecnológico en función de intereses comerciales.

A partir de esto, cabría preguntarse sobre quién ha propiciado el desarrollo de las TIC y qué intereses han estado detrás de ello. La respuesta no es tan sencilla, por ejemplo, se sabe que Internet fue creado por la milicia norteamericana en el contexto de la Guerra Fría, justamente con fines de seguridad nacional frente a la

23 CAstells, Manuel. Prólogo: la red y el yo, op. cit.

24 Ibid., p. 33.

25 Idem. amenaza soviética, pero devino en esta gran red horizontal mundial que permite la comunicación para todo tipo de fines. Podemos apreciar entonces que la tecnología también tiene su propio rumbo, independientemente del control de quien la crea o impulsa.

Economía de la información. Otra característica de nuestra era es la economía basada en la información y el conocimiento, los cuales son concebidos como motores del desarrollo económico pues ahora la producción está enfocada a los bienes y servicios relacionados con la información y el conocimiento; por eso se habla de industrias de la información. Para la unESCO:

La economía del conocimiento pone de manifiesto la complementariedad estructural y tecnológica que existe entre las nuevas posibilidades de codificación, acopio y transmisión de información facilitadas por las nuevas tecnologías, el capital humano de los trabajadores que pueden utilizarlas y una organización "reactiva" de la empresa -gracias a los avances de la gestión del conocimiento- que permiten la explotación más amplia posible del potencial de productividad. ${ }^{26}$

Trabajo. Producto de esta economía de la información, el empleo también se ha transformado, o mejor dicho, se han incrementado las labores relacionadas con la producción y transferencia de información/conocimiento. De hecho, para la unESCO:

la creciente desmaterialización del trabajo individual humano -posibilitada por la sustitución del trabajo manual por las máquinas, y más tarde por el desarrollo de los servicios y el advenimiento de lo virtual con la revolución digital- ha desembocado en el nacimiento de una sociedad en la que el dominio de lo inmaterial siempre confiere más ventajas estratégicas y, por consiguiente, un mayor poder sobre lo material. ${ }^{27}$

Lo importante es destacar que el trabajo de una gran cantidad de la población se trasladó hacia el sector servicios y -en gran medida- hacia las actividades relacio-

\footnotetext{
26 UNESCO. "Sociedades en redes, conocimientos y nuevas tecnologías" [en línea], op. cit., p. 50.

27 Ibid., p. 49.
} 


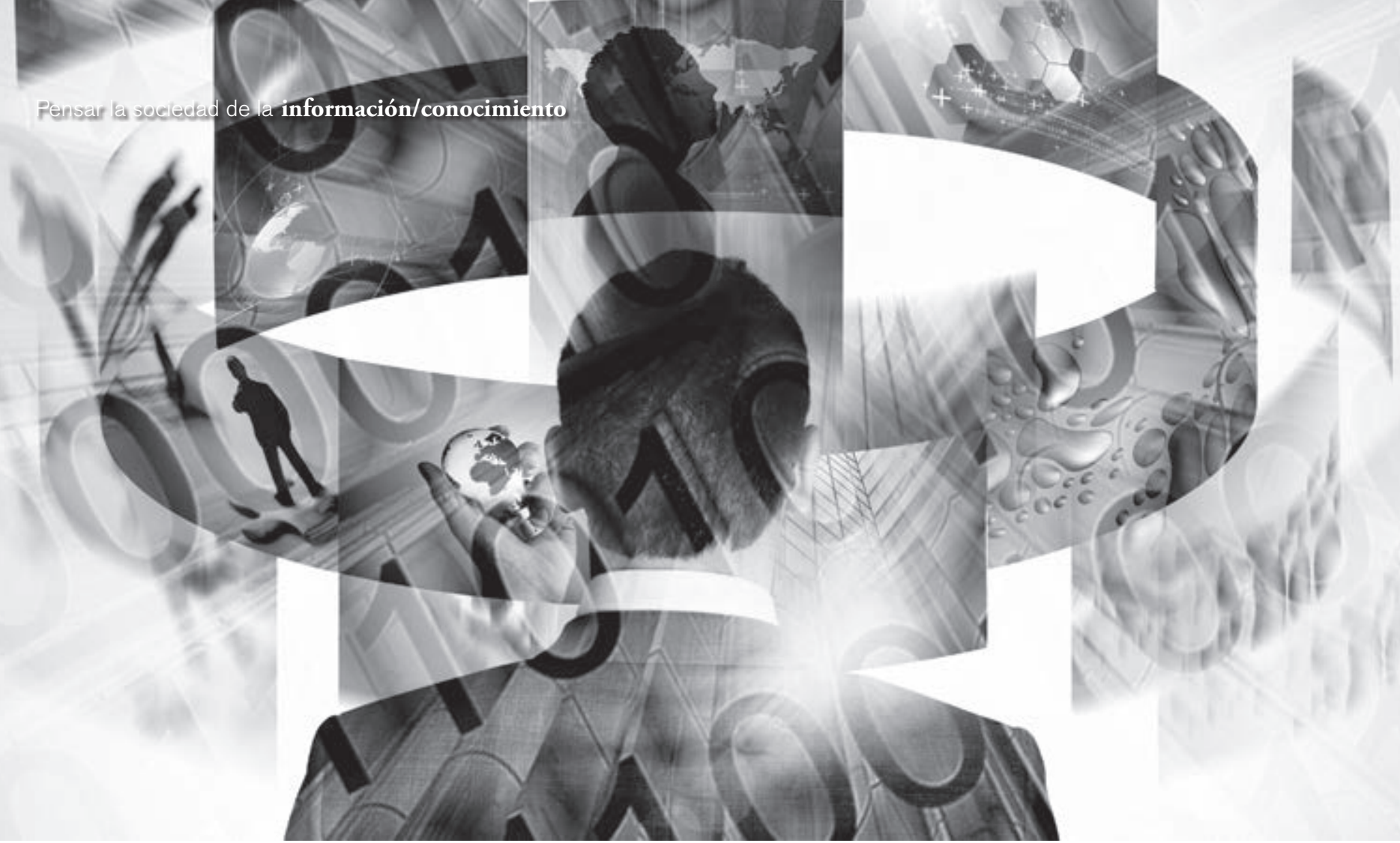

nadas con la información y el conocimiento (educación, telecomunicaciones, consultoría, publicidad, etcétera). Esto significa que cobró relevancia lo inmaterial, lo cual rompió con el paradigma anterior (industrialismo) en el que la materialidad (de la producción) era fundamental. O como dice Webster, "la riqueza de la producción no proviene del esfuerzo físico, sino de las ideas, el conocimiento, las habilidades, el talento y la creatividad". ${ }^{28}$

Redes. A partir de todos los aspectos anteriores (uso de tecnologías, economía y trabajo informacional) se construyeron nuevas redes entre individuos y organizaciones que trascienden fronteras sociales y nacionales. Según la unESCO:

Después de los regímenes de conocimiento basados en la transmisión oral, la escritura y la imprenta, el desarrollo digital ha propiciado una expansión sin precedentes de las redes, en función de dos ejes: uno horizontal de aceleración de las transmisiones, y otro vertical de densificación de las conexiones. Entramos en una era en la que para existir, sobrevivir y no quedar al margen, es necesario comunicar cada vez más, y sobretodo cada vez más de prisa. ${ }^{29}$

28 Webster, Frank, op. cit., p. 27.

29 UNESCO. "Sociedades en redes, conocimientos y nuevas tecnologías" [en línea], op. cit., p. 51.
Hasta aquí se han descrito de manera breve y general las características de la sociedad de la información/ conocimiento. Es momento entonces de hacer la pregunta quizá obvia pero que es la fuente del gran debate: ¿Se trata realmente de un nuevo tipo de sociedad? Desde una perspectiva crítica, distintos autores coinciden en que no se trata de una nueva sociedad. Como lo expresa Rodolfo Suárez:

Concebir, por ejemplo, el estado actual del mundo como una sociedad postindustrial, no sólo tiene como consecuencia un sustancial olvido de que buena parte de la economía, en particular la de los países en vías de desarrollo, sigue estando fuertemente vinculada a la manufactura y a la producción de bienes tangibles. Amén del valor y la cuantía de las "industrias sin chimenea", la tesis puede pasar por alto que la propia "globalización" de las estructuras económicas ha traído consigo una injusta división internacional del trabajo que, de alguna u otra forma, coadyuva a mantener y casi perpetuar la condición de los países subdesarrollados. ${ }^{30}$

30 Suárez, Rodolfo. Introducción. En: Sociedad del conocimiento: propuestas para una agenda conceptual, p. 15. 
Éste es el primer gran cuestionamiento a la llamada sociedad de la información o sociedad del conocimiento; es decir, se trata de un modelo de los países desarrollados, que no tendría mucho que ver con los países subdesarrollados, cuyos problemas sociales y niveles de desigualdad hacen que sólo una pequeñísima parte de la población sea parte de este concierto de información/conocimiento.

Por otro lado, Castells sostiene incluso que no debe llamarse a esta etapa sociedad de la información, él habla de era de la información pues efectivamente la información tiene un papel primordial, pero esto no necesariamente conlleva un nuevo tipo de sociedad. El autor explica la diferencia entre modos de producción, como son el capitalismo o el estatismo, y los modos de desarrollo, como el industrialismo o el informacionalismo. Así pues la nueva estructura social estaría basada en este último como modelo de desarrollo que fungiría como reestructuración del modo de producción capitalista. ${ }^{31}$

Así, el autor concluye:

Aunque la reestructuración del capitalismo y la difusión del informacionalismo fueron procesos inseparables, a escala global, las sociedades actuaron/ reaccionaron de forma diferente ante ellos, según las especificaciones de su historia, cultura e instituciones. Así pues, sería hasta cierto punto impropio referirse a una Sociedad Informacional, que implicaría la homogeneidad de formas sociales en todas partes bajo el nuevo sistema. Ésta es obviamente una proposición insostenible, tanto desde un punto de vista empírico como teórico. No obstante, podríamos hablar de una Sociedad Informacional en el mismo sentido que los sociólogos se han venido refiriendo a una Sociedad Industrial, caracterizada por rasgos fundamentales comunes a sus sistemas sociotécnicos. ${ }^{32}$

Por su parte, Webster argumenta que las definiciones sobre la sociedad de la información ofrecen datos cuantitativos (sobre número de trabajadores o aparatos tecnológicos, porcentajes del PIB destinados a la

1 Castells, Manuel. Prólogo: la red y el yo, op. cit.

32 Ibid., p. 46. información, etcétera), pero que "no existen bases sólidas para asegurar que es un nuevo tipo de sociedad sólo porque hay grandes cantidades de información almacenadas y circulando". ${ }^{33}$ Para él el foco de atención debe estar no en la cantidad sino en la calidad de la información; es decir, desde la perspectiva cuantitativa se suele sumar el valor de las actividades de información en economía y se llega a una cierta cantidad, pero no se toman en cuenta las diferencias cualitativas cruciales dentro de la información. ${ }^{34} \mathrm{El}$ autor pone el ejemplo de un reparador de fotocopiadoras quien es considerado como un trabajador de la información pues usa tecnologías avanzadas, mientras que un granjero es visto como un trabajador netamente manual aunque para su trabajo requiera gran cantidad de información.

Entonces, la propuesta de Webster es que una verdadera sociedad de la información/conocimiento es aquélla en la que el conocimiento teórico dirige todos los procesos sociales; o sea que es aplicado en todos los aspectos de la vida (economía, cultura, política, etcétera). Es decir, en este punto de la modernidad, el ser humano tiene un mayor control de la naturaleza gracias al conocimiento teórico, existe una mayor reflexividad $^{35}$ de actores e instituciones; en pocas palabras, el conocimiento sirve para la toma de decisiones.

Por otro lado, Javier Echeverría ${ }^{36}$ cuestiona la idea de sociedad del conocimiento, en virtud de la propia idea de conocimiento que se desprende de ella. Echeverría sostiene que Drucker únicamente se refirió al conocimiento aplicado, aquél que genera desarrollo tecnológico e innovaciones, con lo cual dejó de lado otros tipos de conocimiento, como por ejemplo, el conocimiento artístico, que siempre ha tenido un impacto social considerable y por lo tanto debería tener un lugar en una sociedad del conocimiento.

\footnotetext{
WeBster, Frank, p. 31.

34 Idem.

35 Término que toma de Giddens (1994) y que puede entenderse como el aumento en las interrogantes del ser humano, individuales y colectivas.

36 Echeverría, Javier, op. cit.
} 
Además, el conocimiento también tiene una dimensión axiológica; es decir que implica valoraciones positivas o negativas; en este sentido el especialista asegura que el conocimiento no sólo tiene ventajas sino puede ser pernicioso cuando se usa en detrimento de la propia humanidad, por ello -dice- no es un bien en sí sino depende de los valores que conformen las sociedades del conocimiento. ${ }^{37}$

Así pues, él habla de una sociedad democrática del conocimiento, y propone el término "repúblicas de conocimiento" en donde precisamente el conocimiento es visto como un bien público compartido, que no es propiedad exclusiva de quien lo generó. El autor concibe pues un proyecto democrático de sociedad de información/conocimiento en el que los usuarios de las TIC "dejen de pensarse a sí mismos como clientes o buscadores de información, y se conciban como ciudadanos de una Telépolis ${ }^{38}$ republicana y confederal en la que se genera e intercambia conocimiento". 39

Por su parte, León Olivé comparte esta visión democrática y sostiene:

Podría replicarse que no es objetable que los beneficios de la comercialización de un producto regresen al capitalista que hizo la inversión, pero que lo éticamente correcto es que el conocimiento, no sólo el que se generó y usó en ese proceso, sino todo el que lo hizo posible y no es fácil hacer explícito, siga siendo un bien público y esté disponible gratuitamente para todo el mundo. ${ }^{40}$

En pocas palabras, de acuerdo con Olivé, "no se trata de discutir el problema de la propiedad privada en general, sino de los medios de producción, incluyendo

37 Idem.

38 Representada como una ciudad-red que consiste en un espacio electrónico entendido como un sistema de redes autónomas e interdependientes entre las que hay flujos de conocimiento (ECHEVERRÍA, 2009).

39 ECheVERríA, Javier, op. cit., p. 62.

40 OLIVÉ, León. ¿A quién pertenece el conocimiento? Poder y contrapoderes en el camino hacia las sociedades del conocimiento. En: Sociedad del conocimiento: propuestas para una agenda conceptual, p. 93. el conocimiento"41, y más aún -dice Olivé- "la propiedad privada del conocimiento es inmoral".42 A partir de esto, el autor es partidario de una sociedad del conocimiento en la que los individuos tienen la capacidad de: a) apropiarse del conocimiento disponible y generado en cualquier parte, b) aprovechar de la mejor forma el conocimiento (científico, tecnológico y tradicional) que históricamente ha producido la sociedad, y c) generar, como sociedad, el conocimiento que se necesite para comprender mejor sus problemas (educativos, económicos, de salud, sociales, ambientales, políticos, etcétera)..$^{43}$ Por ello, este autor habla de "redes sociales de innovación", las cuales estarían encargadas de aprovechar socialmente los conocimientos para resolver problemas (sociales) concretos, lo cual requeriría de la "identificación, recuperación, conservación y fomento de conocimiento tradicional y [...] el refuerzo de la enseñanza y la comunicación de la ciencia y la tecnología". ${ }^{44}$

Parece ser entonces que la que tradicionalmente ha sido llamada sociedad de la información o sociedad del conocimiento puede ser ampliamente cuestionada por una serie de razones, algunas de las cuales he tratado de exponer aquí. Entonces, cabría volver a preguntarse ¿qué es la sociedad de la información/conocimiento?

De nuevo, la respuesta no es fácil ya que -como puede apreciarse- hay distintas interpretaciones, desde perspectivas incluso opuestas. Además el tópico da para una gran discusión pues podríamos tematizar hasta el hartazgo cada uno de los elementos: sociedad, información y conocimiento. Claro que hay todavía mucho que argüir en torno a estas cuestiones. De hecho, se perfila una cada vez más amplia discusión debido a que es un asunto que tiene infinidad de vetas o enfoques de estudio.

Pero, al margen de esto, si tratamos de dar una respuesta concreta de qué es eso de la sociedad de la información/conocimiento, diríamos que es, o puede ser, muchas cosas. Para la UNESCO, por ejemplo, podría ser un proyecto -que involucra muchos otros- de desa-

41 Ibid., p. 94

42 Ibid., p. 96.

43 Idem.

44 Ibid., p. 101. 
rrollo social. Para autores como Echeverría y Olivé es una utopía, un modelo ideal de sociedad en la que la información y el conocimiento están al servicio de la misma. Puede tratarse también de un nuevo metarrelato ${ }^{45}$, lo cual es paradójico en una era en la que supuestamente se acabaron las grandes narrativas (discursos totalizadores) que explican el devenir histórico.

Finalmente, en términos abstractos, la sociedad de la información/conocimiento es una cosa u otra, una idea u otra en función de quién hable de ella. En términos más tangibles, lo que no se puede negar es que es una etapa más del sistema capitalista, que tiene una gran capacidad de reciclarse y para el cual lo que importa son los mercados de consumo de los productos, en este caso, de información/conocimiento. Es por ello que se plantea la duda más profunda sobre si estamos ante una nueva sociedad ${ }^{46}$; es decir, si el sistema no ha cambiado entonces no hay tal nueva sociedad porque no asistimos a nueva configuración (económica, política y social) de las sociedades.

\section{Conclusiones}

A partir de lo anterior, se puede apreciar que el tema de la sociedad de la información y del conocimiento tiene múltiples caras que complican su análisis. Estas facetas son aspectos particulares de todo el fenómeno que llegan a traslaparse unas con otras $y$, de esa manera, se vuelve un entramado tal que puede causar confusiones, ya que de entrada plantea más preguntas que respuestas, tal como lo expresa Voutssás:

\footnotetext{
En esta sociedad empiezan a surgir nuevas preguntas en relación con su principal denominador, la información: ¿quiénes van a controlar las fuentes y diferentes formas de información? ¿quiénes van a distribuirla y cómo? ¿quiénes van a tener acceso a la educación y a la información y cómo? ¿cuánto va a costar la in-

45 O más bien dos grandes metarrelatos opuestos, ya que, como sugiere May, para unos es la aproximación a una gran utopía, mientras que para otros es el camino hacia el futuro descrito en Bladerunner (May, 2002).

46 Castells, Manuel, op. cit., y Mattelart, Armand, op. cit.
}

formación y quién va a pagar por ella? ¿quién la posee legalmente y cómo se transfieren esos derechos? ¿quiénes van a ser los "marginados" de la educación y la información y qué consecuencias tendrá ello en una sociedad de la información? ¿quiénes quedarán excluidos de esa sociedad y por cuánto tiempo? ¿cuáles son los nuevos usos y abusos de la información? y ¿dónde está el límite entre lo público y lo privado? ${ }^{47}$

Así pues, podriamos decir que existen varias dimensiones del problema en cuestión sobre las que se debe reflexionar y discutir; en principio, es necesario puntualizarlas para poder hacer un escrutinio más profundo del tema.

Primero, debemos referir el plano histórico; es decir, el fenómeno del que hablamos se da en una etapa específica del progreso de la humanidad. Se trata de un momento de gran desarrollo y complejización del sistema capitalista que se reconfigura a través de las tecnologías de la información y la comunicación, y que con ello transforma la manera en que los seres humanos se relacionan en múltiples aspectos.

En segundo lugar, relacionado con esto último, hay una dimensión política, entendida ésta como lo que tiene que ver con las relaciones (de poder) entre los seres humanos. El poder estaría determinado por quienes tienen acceso -y de qué manera- a los instrumentos con los que hoy se cuenta para producir todo tipo de bienes y servicios.

Porque, claro, esto tiene un origen económico pues -como vimos- se trata de una nueva fuente de riqueza basada en productos, servicios y procesos relacionados con la información y el conocimiento; para lo cual, se necesita un gran impulso científico y tecnológico orientado precisamente a ese fin; así pues, la ciencia y la tecnología cobran una mayor importancia.

Podriamos hablar también de una perspectiva filosófica, más compleja que las anteriores porque envuelve, a su vez, distintos aspectos. Primero, un matiz ético, pues

\footnotetext{
47 Voutssás MÁRqueZ, Juan. Sociedad de la información, sociedad del conocimiento y bibliotecas digitales. En: Un modelo de planeación de bibliotecas digitales para México, p. 32.
} 
implica una serie de principios y valores en torno a la información/conocimiento y al uso de los mismos. Luego hay un tinte ontológico, que cuestiona el ser individual y social en esta era; es decir, nos lleva al tema de la(s) identidad(es). Finalmente, y precisamente porque se habla del conocimiento, hay una discusión epistemológica pues éste es entendido de distintas maneras.

Por otro lado, hay una vertiente pedagógica, en virtud de que las TIC han planteado nuevas modalidades en el proceso de enseñanza-aprendizaje, lo cual trae consigo el reto de un nuevo tipo de enseñanza, virtual y a distancia, que lleva consigo una nueva relación docente-alumno. Tampoco quiere decir que las TIC o la mayor cantidad de información propicien un aumento o mejoramiento en el nivel educativo.

Asimismo, podemos sugerir una configuración psicosocial, debido a la intersubjetividad que estimulan las redes, de manera social y personal. Esto implicaría -a su vez- el surgimiento de una nueva cultura en torno a los nuevos símbolos que se crean a partir de dichas redes.

A su vez, podemos hablar de una dimensión geográfica pues la espacialidad cobra relevancia en tanto las TIC nos permiten trascender las barreras espacio-temporales. Incluso se trata de una cuestión geopolítica si combinamos el espacio con el tema de las relaciones de poder (económico y político) y de cómo se tienden $y$ entienden las redes.

Por último, y quisiera poner el acento en la parcela bibliotecológica, el fenómeno involucra almacenamiento, organización, transferencia y recuperación de información. Por esta razón este tema concierne a nuestro campo, no sólo porque lo lleve en el nombre sino porque se relaciona con todas y cada una de las labores bibliotecarias.

Pero, yo me pregunto ¿cuál es el papel de los bibliotecarios en este concierto? Como se estima el panorama de la sociedad de la información/conocimiento, o sea de una manera dual opuesta y encontrada, se antoja igual el rol del profesional de la información en esta era. Es decir, desde mi punto de vista habría dos maneras distintas de participar en este proceso. Por un lado están los bibliotecarios vinculados al sector empresarial, quienes entenderían la información y el conocimiento como bienes comercializables. $Y$ por el otro lado encontramos a los bibliotecarios comprometidos con la idea de una sociedad democrática ${ }^{48}$, con lo cual su labor estaría encaminada a una "gestión social" de la información; es decir, facilitar el acceso a la información a todo tipo de usuarios por igual a través una optimización de la organización de la información y el servicio, así como un mayor impulso a la formación de usuarios y -finalmente- el incremento en la oferta de recursos de información de acceso libre.

Personalmente, me identifico con la postura del rol social del bibliotecario, nuestra ética profesional nos dicta un compromiso social ineludible. Considero que precisamente en este momento de la humanidad nuestro papel debe ser protagónico, no sólo como gestores, educadores o servidores, sino como investigadores del propio fenómeno que nos afecta. Finalmente, concuerdo con Ríos en que:

la responsabilidad social del bibliotecólogo, derivada del uso de la información como bien público, abarca la libertad, la prosperidad y el desarrollo de la sociedad y la persona. Los practicantes de la bibliotecología son constructores de las Sociedades del conocimiento, así como también participantes imprescindibles en los procesos de consolidación de la democracia. Transformar la información en un bien público requiere de capacidades cognoscitivas e informacionales, así como de acceso libre e ilimitado al conocimiento, el pensamiento, la cultura y la información. ${ }^{49}$ cos

48 La que Mattelart denomina "Sociedad de los saberes para todos y por todos". Mattelart, Armand, op. cit., p. 3.

49 Ríos ORTEGA, Jaime. La información como bien público: la responsabilidad social del bibliotecólogo. En: Derecho a la información, bien público y bien privado: acceso comunitario y acceso individual, p. 185. 


\section{Obras consultadas}

Becerra, Martín. "La sociedad de la información” [en línea]. Lecciones del Portal. PortalComunicación.Com. <http:// www.portalcomunicacion.com/lecciones.asp? aut $=6>$ [Consultado: 12 abril 2010].

Bell, Daniel. The Coming of Post-Industrial Society. New York: Harper Colophon Books, 1974.

Caldevilla Domínguez, David. Mujeres 2.0. Una visión sobre el consumo de Internet de la mujer de hoy. Revista Icono 14: Revista de Comunicación y Nuevas Tecnologias, 2010, no. 15, p. 326-336. < http://www.icono14.net/revista/num15/22_icono15_davidcaldevilla.pdf $>$ [Consulta: 10 enero 2010].

Castells, Manuel. Prólogo: la red y el yo. En: La era de la información: economía, sociedad y cultura. México: Siglo xx, 2008, vol. I, La Sociedad red, p. 27-53.

Drucker, Peter F. The Age of Discontinuity: guidelines to our changing society. New York: Harper \& Row, 1969. 402 p.

ECHEVerRía, Javier. Las repúblicas del conocimiento. En Sociedad del conocimiento: propuestas para una agenda conceptual. México: unam, 2009, p. 27-62.

Manchlup, Fritz. The Production and Distribution of Knowledge in the United States. Princenton, New Jersey: Princenton University, c1962. 416 p.

Masuda, Yoneji. The Information Society as Post-Industrial Society. Tokyo: Institute for the Information Society, 1980.

Mattelart, Armand. La Sociedad de la información [en línea]: el enfrentamiento entre proyectos de sociedad <http:/ /www. dialogosfelafacs.net/wp-content/uploads/2012/01/67revista-dialogos-la-sociedad-de-la-Informaci $\% \mathrm{C} 3 \% \mathrm{~B} 3 \mathrm{n}$. pdf $>$ [Consultado: 20 junio 2010].

MaY, Christopher. The Information Society: a sceptical review. Reino Unido: Blackwell, 2002.

Morales Campos, Estela. Sociedad e información. Omnia, 1990, vol. 6, no. 20.
Olivé, León. ¿`A quién pertenece el conocimiento? Poder y contrapoderes en el camino hacia las sociedades del conocimiento. En: Sociedad del conocimiento: propuestas para una agenda conceptual. México: UNAM, 2009, p. 89-108.

Ramírez SÁnchez, Sandra Lucía. Conocimiento y sociedad: asimetrías y lugares comunes. En: Sociedad del conocimiento: propuestas para una agenda conceptual. México: UNAM, 2009, p. 63-88.

Ríos Ortega, Jaime. La información como bien público: la responsabilidad social del bibliotecólogo. En: Derecho a la información, bien público y bien privado: acceso comunitario y acceso individual. Coordinación Estela Morales Campos México: unam, Centro Universitario de Investigaciones Bibliotecológicas, 2011, p. 175-186.

SuÁrez, Rodolfo. Introducción. En: Sociedad del conocimiento: propuestas para una agenda conceptual. México: UNAM, 2009 , p. 7-25.

UNESCO. "De la sociedad de la información a las sociedades del conocimiento" [en línea]. En: Hacia las sociedades del conocimiento. París: UNESCO, 2005, p. 29-47. <http:// unesdoc.unesco.org/images/0014/001419/141908s.pdf> [Consultado: 20 mayo 2010].

"Sociedades en redes, conocimientos y nuevas tecnologías" [en línea]. En: Hacia las sociedades del conocimiento. París: UNESCO, 2005, p. 49-60. <http://unesdoc. unesco.org/images/0014/001419/141908s.pdf> [Consultado: 20 mayo 2010].

VoutsSÁs MÁrquez, Juan. Sociedad de la información, sociedad del conocimiento y bibliotecas digitales. En: Un modelo de planeación de bibliotecas digitales para México. México: unam, Centro Universitario de Investigaciones Bibliotecológicas, 2007, p. 27-66.

Webster, Frank. The information society revisited. En: Handbook of new media: social shaping and consequences of ICTS. Edited by Leah A. Lievrouw and Sonia Livingstone. London: Sage, 2002, p. 22-33. 